\title{
PENGARUH HARGA, KEANEKARAGAMAN PRODUK, DAN MINAT BELI TERHADAP KEPUTUSAN PEMBELIAN PADA TOKO ONLINE SHOPEE
}

\author{
EVA ROSDIANA \\ evarosdianaqueen@gmail.com \\ Fakultas Ekonomi dan Bisnis, Universitas Islam Syekh-Yusuf Tangerang \\ HADI SUHARNO \\ hsuharno@unis.a c.id \\ Fakultas Ekonomi dan Bisnis, Universitas Islam Syekh-Yusuf Tangerang \\ UMI KULSUM \\ (ukulsum@unis.ac.id) \\ Fakultas Ekonomi dan Bisnis, Universitas Islam Syekh-Yusuf Tangerang \\ evarosdianaqueen@gmail.com
}

\begin{abstract}
This research was conducted at the Online Shopee among the Faculty of Law students of the Islamic University of Syekh Yusuf, Tangerang. The method used was SPSS version 25, a population of 700 people with a sample of 88 people. And in this research using descriptive analysis, validity test, reliability test, normality test, multicollinearity test, heterokedasticity test, autocorrelation test, regression analysis, correlation analysis, $t$ test, $F$ test, and coefficient of determination The results of this research are price variables, diversity product, and buying interest have a significant effect on purchasing decisions.
\end{abstract}

\section{A. PENDAhUluan}

Internet salah satu jaringan/situs yang memudahkan orang untuk melakukan komunikasi. Pada zaman modern ini, dengan internet yang semakin canggih dan berkembang membuat orang dengan mudah melakukan transaksi lewat online maupun offline. Baik itu membeli pakaian, kecantikan, perlengkapan rumah, elektronik, buku, alat tulis, makanan dan minuman, bahkan kebutuhan-kebutuhan orang lainnya bisa melalui internet dengan menggunakan smarphone yang dimilikinya

Menurut Ketua umum Asosiasi Penyelenggaraan Jasa Internet Indonesia (APJII)(dalam Fransiska Vania Sudjatmika 2017) Jamalul Izza pada tanggal 23 Agustus 20I6, pengguna internet di Indonesia mencapai I33 juta pengguna. Angka ini meningkat dibanding dengan tahun 2015, yang mana jumlah pengguna internet di Indonesia berjumlah $88, \mathrm{I}$ juta pengguna.

Pada tahun 2019 ini internet semakin canggih dapat mengubah pola pikir manusia dalam segi kehidupan sehari-hari.Namun sejak adanya onlineshop semua orang lebih memilih belanja lewat online shop.Karena banyaknya kebutuhan membuat konsumen lebih memilih melakukan pembelian melalui onlineshop, yaitu memberikan kemudahan transaksi, pelanggan tidak perlu mendatangi toko, pelanggan lebih mudah mencari barang atau produk yang diinginkan melalui smartphone yang dimilikinya kapanpun dan dimanapun.

Di tahun 2019 banyak konsumen menggunakan online Shopeeuntuk transaksi belanja.Online shopee merupakan perdagangan onlineshop yang menyajikan berbagai macam kebutuhan konsumen baik kebutuhan primer maupun sekunder (sumber: https://id.m.wikipedia.org/wiki/Shopee). 
Baru baru ini Online shopee menawarkan produk dengan harga yang murah, harga yang terjangkau, banyaknya potongan pembelian dan gratis ongkir membuat para konsumen tertarik melakukan keputusan pembelian secara online.

Online shopee juga menawarkan beragam macam produk, mulai dari jenis-jenis produk yang beragam, desain produk yang beragam, ukuran produk yang beragam, dan bahan produk yang beragam dapat menarik para konsumen akan terus melakukan keputusan pembelian secara online.

Minat beli kecenderungan seseorang untuk membeli suatu merek/mengambil tindakan yang berhubungan dengan pembelian. Kehadiran onlne shopee dan fitur akses layanan kapanpun dan dimanapun membuat penilain yang lebih dimata konsumen apabila konsumen tertarik/senang dengan barang/produk maka konsumen akan melakukan pembelian. Semakin tingginya minat beli maka semakin tinggi pula keputusan pembelian

Berdasarkan uraian yang telah dijelaskan diatas, bahwa faktor-faktor yang akan diteliti masih dirasa kurang oleh peneliti diantaranya. Maka peneliti tertarik mengenai pengaruh harga, keanekaragaman produk, dan minat beli dan mencari pengaruhnya terhadap keputusan pembelian. Dan dapat disimpulkan peneliti akan melakukan penelitian dengan judul "Pengaruh Harga, Keanekaragaman Produk, Dan Minat Beli Terhadap Keputusan Pembelian Pada Toko Online Shopee".

\section{I.I. Identifikasi Masalah}

Dapat disimpulkan berdasarkan latar belakang masalah diatas, bahwa Pengaruh keputusan pembelian sangatlah penting bagi konsumen yang ingin melakukan pembelian. Sehingga peneliti mengidentifikasikan beberapa masalah yang terkait dalam mengambil keputusan pembelian.

I. Keputusan pembelian dipengaruhi oleh harga.

2. Keputusan pembelian dipengaruhi oleh keanekaragaman produk.

3. Keputusan pembelian dipengaruhi oleh minat beli.

4. Harga, keanekaragaman produk, dan minat beli mempengaruhi keputusan pembelian.

\section{I.2. Tujuan Penelitian}

Tujuan dari penelitian ini adalah:

> Untuk mengetahui harga terhadap keputusan pembelian pada toko online shopee.

$>$ Untuk mengetahui pengaruh keanekaragaman produk terhadap keputusan pembelian pada toko online shopee.

$>$ Untuk mengetahui pengaruh minat beli terhadap keputusan pembelian pada toko online shopee.

$>$ Untuk mengetahui harga, keanekaragaman produk, dan minat beli terhadap keputusan pembelian pada toko online shopee.

\section{Landasan Teori, Keranka Pemikiran Dan Hipotesis}

\section{I. Pengertian Harga}

Menurut Arief Rakhman Kurniawan (C) (2018:23) harga merupakan "salah satu penentu keberhasilan keberhasilan suatu perusahaan karena harga menentukan seberapa besar keuntungan yang akan diperoleh perusahaan setelah produk itu terjual kekonsumen".

\subsection{Pengertian Keanekaragaman Produk}

Menurut Kotler (F) (dalam Nuri Mahdi Arsyanti dkk 2016) merupakan 'kumpulan seluruh produk dan barang yang ditawarkan penjual tertentu kepada pembeli' 


\subsection{Pengertian Minat Beli}

Menurut Rubianti (dalam Rosian Anwar \& Wijaya Adidarma, 2016) 'minat beli yang dilakukan dengan media online adalah seseorang untuk membeli suatu produk yang ditawarkan oleh produsen kepada konsumen melalui media online'.

\subsection{Pengertian Keputusan Pembelian}

Menurut Kotler \& Keller (B) (dalam Sanny Hanjaya 2016) keputusan pembelian merupakan 'sebuah proses dimana konsumen mengetahui masalah yang dihadapi, selanjutnya mencari informasi produk atau merek dan mengevaluasi masing-masing. pilihan yang dapat menyelesaikan masalah tersebut sehingga mengarah pada keputusan pembelian'. Menurut salah satu hadist yang menjelaskan keputusan pembelian yaitu perilaku konsumen adalah:

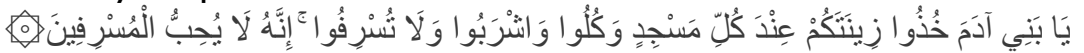

"Hai anak Adam, pakailah pakaianmu yang indah di setiap (memasuki) masjid, makanlah dan minumlah, dan janganlah berlebih-lebihan. Sesungguhnya Allah tidak menyukai orang-orang yang berlebih-lebihan'(QS. Al-A'raf: 3I)."

rl : Hubungan antara harga terhadap keputusan pembelian.

r2 : Hubungan antara keanekaragaman produk terhadap keputusanPembelian

r3 : Hubungan antara minat beli terhadap keputusan pembelian

$\mathrm{R}$ : Hubungan antara harga, keanekaragaman produk, dan minatbeli bersama-sama terhadap keputusan pembelian.

\section{B. METODE PENELITIAN}

\section{I. Metode Penelitian}

Penelitian ini menggunakan penelitian kausal untuk mengetahui antara dua variabel atau lebih.Metode yang digunakan dalam penelitian ini adalah metode surveY Penelitian ini menggunakan penelitian kausal untuk mengetahui antara dua variabel atau lebih.Metode yang digunakan dalam penelitian ini adalah metode survey yaitu penelitian dilakukan dengan terjun langsung ke lapangan dengan menyebar angket atau kuesioner sebagai instrumen pengumpulan data dan dibantu menggunakan SPSS versi 25 . Sampel dalam penelitian ini peneliti ambil, yaitu metode non probabilitas sampling. Penelitiaan dilakukan di online shopee dikalangan mahasiswa Fakultas Hukum Universitas Islam Syekh Yusuf Tangerang Tahun Akademik 2018/2019.Dengan jumlah 88 responden dari populasi 700 orang.Dalam penelitan ini menggunakan analisis deskriptif, uji validitas, uji reliabilitas, uji normalitas, uji multikolonieritas, uji heterokedastisitas, uji autokorelasi, analisis regresi, analisis korelasi, uji t, uji F, dan koefisien determinasi.

\subsection{Rancangan Uji Hipotesis}

$\mathrm{H}_{\mathrm{ol}}$ : Tidak terdapat pengaruh yang positif dan signifikan antara hargadengan keputusan pembeliaN.

$\mathrm{H}_{\mathrm{o} 2}$ : Tidak terdapat pengaruh yang positif dan signifikan antara keanekaragaman produk terhadap keputusan pembelian.

$\mathrm{H}_{\mathrm{o3}}$ : Tidak terdapat pengaruh yang positif dan signifikan antara minat beli terhadap keputusan pembelian.

$\mathrm{H}_{\circ 4}$ : Tidak terdapat pengaruh yang positif dan signifikan antara pengaruh harga, keanekaragaman produk, dan minat beli terhadap keputusan pembelian.

$\mathrm{H}_{\mathrm{al}}$ : Terdapat pengaruh yang positif dan signifikan antara harga terhadap keputusan pembelian.

$\mathrm{H}_{\mathrm{a} 2}$ : Terdapat pengaruh yang positif dan signifikan antara keanekaragaman produk terhadap keputusan pembelian. 
$\mathrm{H}_{\mathrm{a} 3}$ : Terdapat pengaruh yang positif dan signifikan antara minat beli terhadap keputusan pembelian.

$\mathrm{H}_{\mathrm{a} 4}$ : Terdapat pengaruh yang positif dan signifikan antara pengaruh harga, keanekaragaman produk, dan minat beli terhadap keputusan pembelian.

\section{HASIL PENELITIAN}

\section{I Hasil Metode Analisis Data}

$>$ Uji Validitas

Berdasarkan hasil uji korelasi validitas, maka dapat diketahui rekapitulasi data variabel $X_{1}, X_{2}$, dan $X_{3}$ dan $Y$ dari butir pertanyaan I s/d 28 dinyataakan valid. Untuk mengethui hasil $r_{\text {tabel }}$ diperoleh dari $\mathrm{df}=\mathrm{n}-2$ yaitu $88-2=86$ dengan tingkat signifikan uji dua arah 0,05 . Maka hasil $r_{\text {tabel }}$ dari $(88 ; 0,05)$ adalah 0,1765 . Instrument nyatakan valid apabila $r_{\text {hitung }}>r_{\text {tabel. }} r_{\text {hitung }}$ dari kuesoner yang disebarkan ke 88 responden adalah diatas 0,1765 yang artinya pertanyaan-pertanyaan yang di sebaran valid.

\section{$>$ Uji Reliabilitas}

Berdasarkan hasil uji reliabilitas dari variabel harga, keanekaragaman produk, dan minat beli, terhadap keputusan pembelian dapat disimpulkan bahwa seluruh variabel dinyatakan reliable karena memiliki nilai Cronbach's Alpha>0,6.

\section{$>$ Uji Normalitas}

\begin{tabular}{llc}
\multicolumn{2}{c}{ One-Sample Kolmogorov-Smirnov Test } \\
\hline $\mathrm{N}$ & \multicolumn{1}{c}{$\begin{array}{c}\text { Unstandardized } \\
\text { Residual }\end{array}$} \\
\hline Normal Parameters & & 88 \\
\hline Most & Mean & .0000000 \\
\cline { 2 - 3 } & Std. Deviation & 1.87459861 \\
\hline Test Statistic & Absolute & .063 \\
\cline { 2 - 3 } & Positive & .062 \\
\cline { 2 - 3 } & Negative &. .063 \\
\hline Asymp. Sig. (2-tailed) & & .063 \\
\hline a. Test distribution & & .200 c,d
\end{tabular}

a. Test distribution is Normal.

b. Calculated from data.

c. Lilliefors Significance Correction.

d. This is a lower bound of the true significance.

Sumber: data primer yang diolah menggunakan SPSS versi 25.

Berdasarkan tabel yang telah didapat diatas dalam uji normalitas menghasilkan Asymtonic Significance $0,200>0,05$. Berdasarkan hasil tabel diatas bahwa pola memiliki distribusi yang normal, bahwa model uj regresi berganda memenuhi asumsi normal. 


\section{Uji Multikolonieritas}

\section{Coefficients ${ }^{a}$}

\begin{tabular}{|c|c|c|c|c|c|c|c|}
\hline \multirow[b]{2}{*}{ Model } & \multicolumn{4}{|c|}{$\begin{array}{c}\text { Unstandardized Standardized } \\
\text { Coefficients } \\
\text { Coefficients }\end{array}$} & \multirow[b]{2}{*}{ Sig. } & \multicolumn{2}{|c|}{$\begin{array}{l}\text { Collinearity } \\
\text { Statistics }\end{array}$} \\
\hline & Bp & Error & Beta & $\mathbf{t}$ & & Tolerance & VIF \\
\hline (Constant) & 31.170 & 5.075 & & 6.142 & .000 & & \\
\hline HARGA & -.074 & .092 & -.085 & -.809 & .421 & .973 & 1.028 \\
\hline $\begin{array}{l}\text { KEANEKARAMAN } \\
\text { PRODUK }\end{array}$ & .299 & .106 & .303 & 2.813 & .006 & .920 & 1.087 \\
\hline MINAT BELI & -.126 & .123 & -.109 & 1.023 & .309 & .943 & 1.061 \\
\hline
\end{tabular}

a. Dependent Variable: KEPUTUSAN PEMBELIAN

Berdasarkan hasil output pada tabel diata diketahui:

I. Variabel Harga $(X I)$ memiliki nilai

Torelance $0,973>0,0 \mathrm{I}$ dan nilai VIF dan nilai VIF I,028 $<10,00$ yang berarti tidak terjadi multikolonieritas.

2. Variabel Keanekaragaman Produk

(X2) memiliki nilai torelance $0,920>0,0$ I dan nilai VIF I,087 $<10,00$ yang berarti bahwa tidak terjadi multikolinieritas.

3. Variabel Minat Beli (X3) memiliki

nilai Tolerance $0,943>0,0 \mathrm{I}$ dan Nilai VIF I,06I yang berarti bahwa tidak terjadi multiolonieritas.

4. Nilai Torelance semua variabel independen lebih besar dar 0,10

5. Nilai VIF semua varaibel independen lebih kecil dari 10,00

\section{$>$ Uji Heterokedastisitas}

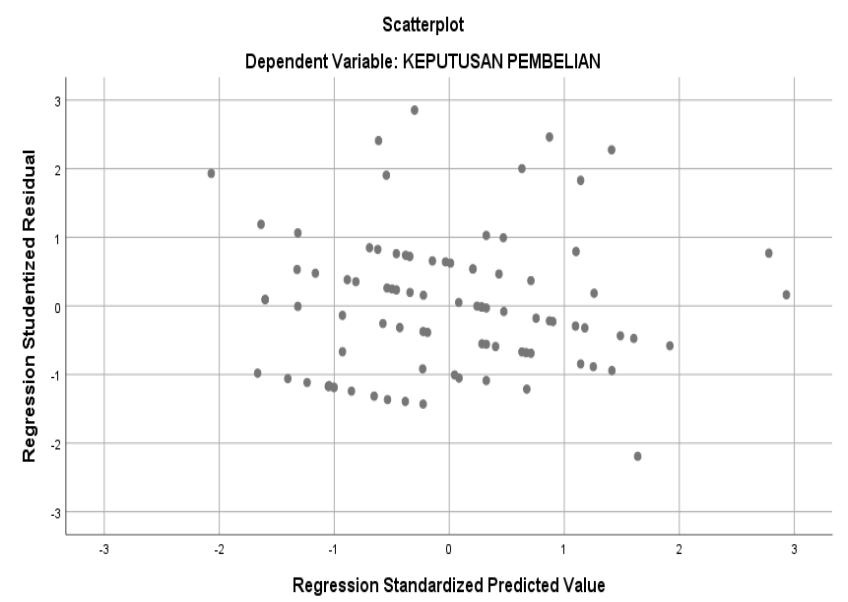

Berdasarkan gambar terlihat bahwa titik-titik menyebar secara acak serta tersebar di atas dan dibawah angka 0 pada sumbu $Y$. ini dapat disimpulkan bahwa tidak terjadi heterokedstisitas pada model regresi ini. 
Uji Autokorelasi

Model Summaryb

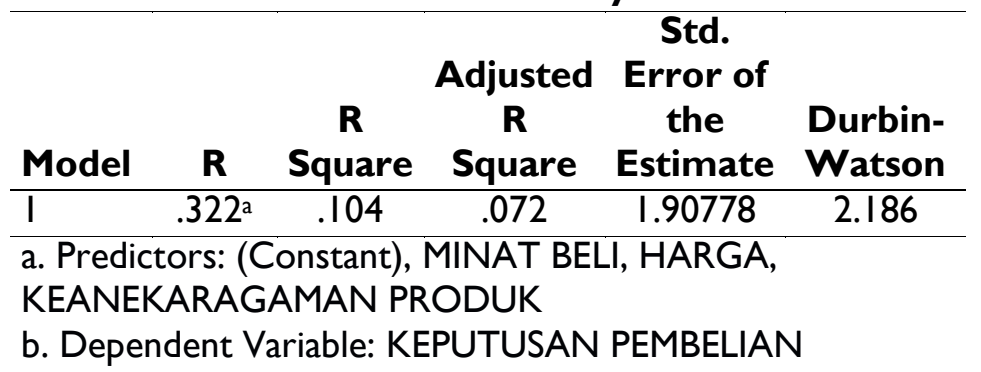

Berdasarkan tabel diatas nilai Durbin Watson sebesar 2,186 nilai Durbin Watson dibandingkan dengan nilai tabel, dengan menggunakan nilai signifikansi $5 \%$ dengan jumlah 3 variabel independent dan I variabel dependen $(k=3)$ dengan jumlah sampel sebanyak $88(n=88)$. Besarnya Durbin Watson tabel untuk DL (batas luar) = 1.583 dan besarannya Durbin Watson tabel untung DU (batas dalam) $=1.724$. Besarnya nilai $4-\mathrm{DL}(4-\mathrm{I} .583=2.417)$ dan nilai $4-$ DU $(4$ - I.724 = 2.276).Selanjutnya nilai DW dibandingkan dengan nilai dU dan 4-DU yang terdapat dalam tabel Durbin Watson. Pengambilan keputusaan ini dilakukan dengan ketentuan DU $<$ d $<4$-DU atau $1.724<2.186<2.276$. Maka disimpulkan bahwa tidak terdapat masalah autokorelasi pada variabel yang digunakan dalam penelitian ini.

$>$ Hasil Analisis Regresi Berganda

\begin{tabular}{llccccc}
\multicolumn{7}{c}{ Coefficients $^{\mathbf{a}}$} \\
\hline Model & & $\begin{array}{c}\text { Unstandardized } \\
\text { Coefficients } \\
\text { Std. }\end{array}$ & $\begin{array}{c}\text { Standardized } \\
\text { Coefficients }\end{array}$ \\
\hline I & B & Error & Beta & t & Sig. \\
\hline & (Constant) & 31.170 & 5.075 & & 6.142 & .000 \\
& HARGA (XI) & -.074 & .092 & -.085 & -.809 & .421 \\
& KEANEKARAGAMAN & .299 & .106 & .303 & 2.813 & .006 \\
& PRODUK (X2) & & & & & \\
& MINAT BELI (X3) & -.126 & .123 & -.109 & -1.023 & .309 \\
\hline
\end{tabular}

a. Dependent Variable: KEPUTUSAN PEMBELIAN (y)

Berdasarkan hasil uji regresi berganda pada tabel diatas, diperoleh persamaan regresi sebagai berikut:

$Y=31.170+0,074 X_{1}+0,299 X_{2}+0,126 X_{3}$

Berdasarkan rumus diatas dapat dijelaskan sebagai berikut:

I. Konstanta sebesar 3I,I70 artinya,

2. jika harga, keanekaragaman produk, dan minat beli nilainya 0 maka keputusan pembelian nilainya meningkat sebesar 3I, I70.

3. Koefisien regresi Harga (XI)

4. bernilai $-0,074$, artinya setiap penurunan I satuan harga akan menurunkan keputusan pembelian sebesar $-0,074+31,170=31,244$ dengan anggapan bahwa variabel lain nilainya tetap.

5. Koefisien regresi Keanekaragaman

6. Produk (X2) bernilai 0, 299 artinya jika penambahan sebsear satuan pelayanan, maka penilaian keanekaragaman produk setiap kenaikan I satuan Keanekaragaman Produk akan 
meningkatkan Keputusan Pembelian sebesar 0, 299+3I, I 70=3I,469 dengan anggapan bahwa variabel lain nilainya tetap.Koefisien regresi Minat Beli (X3) bernilai $-0,126$, artinya setiap penurunan I satuan Minat Beli akan Menurunkan Keputusan Pembelian sebesar $0,126+31,170=31,296$ dengan angapan bahwa variabel lain nilainya tetap.

$>$ Uji Korelasi Berganda

Model Summary

\begin{tabular}{|c|c|c|c|c|c|c|c|c|c|}
\hline \multirow[b]{2}{*}{ Model } & \multirow[b]{2}{*}{$\mathbf{R}$} & \multirow[b]{2}{*}{$\begin{array}{c}\mathbf{R} \\
\text { Square }\end{array}$} & \multirow[b]{2}{*}{$\begin{array}{c}\text { Adjusted } \\
\mathbf{R} \\
\text { Square }\end{array}$} & \multirow{2}{*}{$\begin{array}{c}\text { Std. } \\
\text { Error of } \\
\text { the } \\
\text { Estimate }\end{array}$} & \multirow[b]{2}{*}{$\begin{array}{c}\text { R } \\
\text { Square } \\
\text { Change }\end{array}$} & \multicolumn{4}{|c|}{ Change Statistics } \\
\hline & & & & & & $\begin{array}{c}F \\
\text { Change }\end{array}$ & df I & df2 & $\begin{array}{c}\text { Sig. F } \\
\text { Change }\end{array}$ \\
\hline I & $.322^{\mathrm{a}}$ & .104 & .072 & 1.908 & .104 & 3.238 & 3 & 84 & .026 \\
\hline
\end{tabular}

a. Predictors: (Constant), Minat Beli, Harga , Keanekaragaman Produk

Berdasarkan hasil uji korelasi berganda menunjukan bahwa nilai Sig. $\mathrm{F}$ change $<0,05=$ $0,026>0,05$ menunjukan bahwa variabel independen $(X)$ memiliki hubungan korelasi terhadap variabel $(Y)$ dengan nilai person correlation sebesar 0,322 dengan tingkat hubungan yang sedang. Jadi secara simultan variabel harga, keanekaragaman produk, dan minat beli memiliki hubungan terhadap keputusan pembelian dengan tingkat interpretasi yang sedang.

$>$ Uji t

\begin{tabular}{|c|c|c|c|c|c|c|}
\hline \multicolumn{7}{|c|}{ Coefficients ${ }^{a}$} \\
\hline \multirow{2}{*}{\multicolumn{2}{|c|}{ Model }} & \multicolumn{2}{|c|}{$\begin{array}{l}\text { Unstandardized } \\
\text { Coefficients }\end{array}$} & \multirow{2}{*}{$\begin{array}{c}\text { Standardized } \\
\text { Coefficients } \\
\text { Beta }\end{array}$} & \multirow{3}{*}{$\frac{t}{6.142}$} & \multirow{3}{*}{$\begin{array}{l}\text { Sig. } \\
.000\end{array}$} \\
\hline & & B & Std. Error & & & \\
\hline $\mathrm{I}$ & (Constant) & 31.170 & 5.075 & & & \\
\hline & HARGA (XI) & -.074 & .092 & -.085 & -.809 & .421 \\
\hline & $\begin{array}{l}\text { KEANEKARAGAMAN } \\
\text { PRODUK }(X 2)\end{array}$ & .299 & .106 & .303 & 2.813 & .006 \\
\hline & MINAT BELI (X3) & -.126 & .123 & -.109 & -1.023 & .309 \\
\hline
\end{tabular}

a. Dependent Variable: KEPUTUSAN PEMBELIAN (y)

Berdasarkan hasi uji t pada tabel menunjukkan bahwa:

I. Variabel Harga

Variabel harga memiliki nilai signifikan sebesar 0,42 I nilai ini lebih besar dari 0,05 $(0,421>$ 0,05). Ini berarti Ho diterima dan $\mathrm{Ha}$ ditolak.sehingga dapat disimpulkan variabel harga secara parsial tidak berpengaruh signifikan terhadap variabel keputusan pembelian.

2. Variabel Keanekaragaman Produk

Variabel keanekaragaman produk memiliki nilai signifikan sebesar 0,006 nilai ini lebih kecil dari $0,05(0,006>0,05)$. Ini berarti Ho ditolak dan Ha diterima sehingga dapat disimpulkan variabel keanekaragaman produk secara parsial berpengaruh signifikan terhadap variabel keputusan pembelian.

3. Variabel Minat Beli

Variabel minat/beli memiliki nilai signifikan sebesar 0,309 nilai ini lebih besar dari 0,05 (0,309 > 0,05). Ini berarti Ho diterima dan $\mathrm{Ha}$ ditolak dapat disimpulakan bahwa variabel minat beli secara parsial tidak berpengaruh signifikan terhadap variabel keputusan pembelian. 


\begin{tabular}{|c|c|c|c|c|c|c|}
\hline \multicolumn{7}{|c|}{ ANOVAa } \\
\hline \multicolumn{2}{|c|}{ Model } & $\begin{array}{l}\text { Sum of } \\
\text { Squares }\end{array}$ & Df & $\begin{array}{l}\text { Mean } \\
\text { Square }\end{array}$ & $\mathbf{F}$ & Sig. \\
\hline I & Regression & 35.351 & 3 & 11.784 & 3.238 & .026 \\
\hline & Residual & 305.728 & 84 & 3.640 & & \\
\hline
\end{tabular}

a. Dependent Variable: KEPUTUSAN PEMBELIAN (y)

b. Predictors: (Constant), MINAT BELI (X3), HARGA (XI), KEANEKARAGAMAN PRODUK (X2)

Hasil dari perhitungan nilai $f$ hitung dari model adalah 3.238 dengan nilai probabilitas sebesar 0,026 . besar nilaai $f$ tabel dengan level signifikan $a=5 \%(0,05)$ dengan derajat pembilang $\mathrm{df}=\mathrm{k}-\mathrm{I}$ (jumlah variabel- $\mathrm{I}$ ) atau $3-\mathrm{I}=2$, dan derajat penyebut digunakan $\mathrm{df}=\mathrm{n}-\mathrm{k}-\mathrm{I}$ (jumlah sampel-jumlah variabel independen atau 88-3-I=84 maka diperoleh angka 2,7I karena $\mathrm{f}$ hitung > $f$ tabel $(3.238>2,7 \mathrm{I})$. Maka Ho ditolak dan Ha diterima yang berarti model regresi, dapat digunakan untuk memprediksi kepuasan konsumen,atau dapat dikatakan bahwa ketiga variabel yakni harga, keanekaragaman produk, dan minat belibersama-sama berpengaruh dan terdapat hubungan yang positif dan signifikan.

\section{$>$ UjiKoefisien Determinasi}

Model Summaryb

\begin{tabular}{lcccc}
\hline Mode & $\mathbf{R}$ & $\begin{array}{c}\mathbf{R} \\
\text { Square }\end{array}$ & $\begin{array}{c}\text { Adjusted R } \\
\text { Square }\end{array}$ & $\begin{array}{c}\text { Std. Error } \\
\text { of the } \\
\text { Estimate }\end{array}$ \\
\hline I & $.322^{\mathrm{a}}$ & .104 & .072 & 1.908
\end{tabular}

a. Predictors: (Constant), MINAT BELI, HARGA, KEANEKARAGAMAN PRODUK

b. Dependent Variable: KEPUTUSAN PEMBELIAN

Berdasarkan tabel diatas diketahui bahwa $R$ squeare $=0,104$ atau $(10,4 \%)$ artinya pengaruh HArga (XI), Keanekaragaman Produk (X2), dan Minat Beli (X3) terhadap Keputusan Pembelian (Y) adalah sebesar $(10,4 \%)$ dan sisanya $(89,6)$ dipengaruhi oleh faktor lain atau variabel lain selain independen tersebut.

\section{KESIMPULAN DAN SARAN}

\section{I Kesimpulan}

Penelitian ini bertujuan untuk mengetahui pengaruhnya harga, keanekaragaman produk, dan minat beli terhadap keputusan pembelian yang dilakukan oleh mahasiswa fakultas hukum universitas islam syekh yusuf tangerang tahun akademik 2018/2019 pada toko online shoppe. Dari rumusan masalah, hasil analisis data, hingga berbagai pembahasan yang dikemukakan oleh peneliti, dapat disimpulan:

I. Melalui perhitungan statistik secara

2. uji parsial yang didapat, disimpulkan bahwa harga tidak berpengaruh secara parsial terhadap keputusan pembelian dikarenakan ketidak stabilan harga.

3. Melalui perhitungan statistik uji 
4. parsial yang didapat, disimpulkan bahwa keanekaragaman produk berpengaruh secara parsial terhadap keputusan pembelian.

5. Melalui hasil perhitungan statstik uji

6. parsial yang didapat, disimpulkan bahwa minat beli tidak berpengaruh secara parsial terhadap keputusan pembelian dikarenakan kurangnya pemanfaatan fitur mengakibatkan menurunnya minat beli konsumen melakukan pembelian.

7. Melalui hasil perhitungan statistic

8. uji simultan yang didapat, disimpulkan bahwa harga, keanekaragaman produk, dan minat beli berpengaruh secara simultan terhadap keputusan pembeian pada toko online shopee.

\subsection{SARAN}

\section{a. Bagi Perusahaan}

Berdasarkan hasil penelitian yang menyatakan bahwa harga tidak berpengaruh terhadap keputusan pembelian pada marketplace shopee, pihak shopee harus terus meningkatkan produk dengan harga yang terjangkau serta kesesuaian harga dengan kualitas dan manfaat, agar tidak ada lagi masalah harga yang tidak berubah/stabil agar konsumen tidak beralih kepesaing. Pada variabel keanekaragaman produk perusahaan harus lebih memperbanyak jumlah produk, baik dalam segi ukuran, bahan, design, dan jenis produk agar apa yang dibutuhkan konsumen terpenuh. Pada variabel minat beli perusahaan meningkatkan kualitas fitur dan layanan agar dapat memperkuat persepsi konsumen tentang marketplace shopee.

\section{E. DAFTAR PUSTAKA}

Ade Aminudin Charlis, Patricia Diana P, \& Moh Mukery Warso." Pengaruh Keanekaragaman Produk, Kualitas Pelayanan, dan Kepercayaan Terhadap Keputusan Konsumen Giant Supermarket Puri Anjasmoro Semarang”.

Andrew Gustnest Binalay, Silvya L. Mandey, Christoffel M. O. Mintardjo. Pengaruh Sikap, Norma Subjektif Dan Motivasi Terhadap Minat Beli Secara Online Pada Mahasiswa Fakultas Ekonomi Dan Bisnis Di Manado. Jurnal Emba 397 Vol.4 No.I.

Aptaguna, A, Pitaloka, E. (2016). Pengaruh Kualitas Layanan Dan Harga Terhadap Minat Beli Jasa Go-Jek. Pengaruh Kualitas Layanan Dan Harga Terhadap Minat Beli Jasa Go-Jek. Widyakala Volume 3 Maret 2016 ISSN : 2337-73I 3 print.

Arief Rakhman Kurniawan. (20l8). Dasar-Dasar Marketin; Segala Hal Tentang Marketing \& Sales.Yogyakarta.Quadrant.

Asri Nugrahani Ardianti. Pengaruh Online Customer Review dan Online Customer Rating terhadap Keputusan Pembelian melalui Marketplace Shopee.(Studi pada Mahasiswa Aktif FISIP Undip).

Citra Sugianto Putri. (2016). "Pengaruh media Sosian Terhadap Keputusan Pembelian Konsumen Cherie Melalui Minat Beli”. Manajemen dan Start-Up Bisnis Volume I, nomor 5

Cholifatun Nisak.Pengaruh Harga, Keragaman Model Produk, Kualitas Informasi Dan Kepercayaan Terhadap Keputusan Pembelian Online Pada Toko Tas Online Sabilla Store

Danang Sunyoto, S.H., S.E., M.M. (20I4). Konsep Dasar Riset Pemasaran \& Perilaku Konsumen.Yogyakarta.CAPS (Center for Academic PublishingService). 
Dewi Kurniawati \& Nugraha Arifin.Strategi Pemasaran Melalui Media Sosial dan Minat Beli Mahasiswa.

Fandy Tjiptono, Ph.D. (2017). Strategi

Pemasaran.Yogyakarta.CV.

Andi Offset.

Fransiska Vania Sudjatmika. (2017). “Pengaruh Harga, Ulasan Produk, Kemudahan, dan Keamanan Terhadap Keputusan Pembelian Secara Online di Tokopedia.com”. Agora Vol. 5, No. I.

Giri Maulana Arief \& Heppy Millianyani.(20I5). Pengaruh Social Media Marketing Melalui Instagram Terhadap Minat Beli Konsumen Sugar Tribe. E-Proceeding Of Management : Vol.2, No.3.

Hendro Yuwono, Syamswana Yuwana. (2017). Pengaruh Kualitas Pelayanan Dan Keragaman Produk Terhadap Kepuasan Konsumen Pada Toko King Di Malang.Volume 2, Nomor I.

I.G.A Yulia Purnamasari. (20I5). Pengaruh Kualitas Produk Dan Harga Terhadap Kepuasan Konsumen Produk M2 Fashion Online Di Singaraja Tahun 2015. Jurnal Jurusan Pendidikan Ekonomi (JJP) Volume: 5 Nomor: I.

Ilham Tugiso, Andi Tri Haryono, Maria M Minarsih. (2016). Pengaruh Reationship Marketing, Keamanan, Kepercayaan dan Kualitas Pelayanan Terhadap Keputusan Pembelian Online Shop dan Loyalitas Konsumen Sebagai Variabel Intervening (Study Kasus Pada Onlineshop "NUMIRA" Semarang).Journal of Management, Volume 2 No.2.

Marisa Arnindita Palma \& Anik Lestari Andjarwat.(2016). Pengaruh Kualitas Produk, Kemudahan, Dan Harga Terhadap Niat Beli Ulang Dengan Kepuasan Sebagai Variabel Intervening (Studi Pada Pelanggan Produk Fashion Melalui Toko online di Surabaya). Volume 16, No. I, Januari - Juni (Semester I) 2016, Halaman 84-I 04.

Nafisa Choirul Mar'ati. Pengaruh Kualitas Layanan Dan Harga Terhadap Kepuasan Pelanggan Jasa Transportasi Ojek Online (Studi Pada Konsumen Gojek Di Surabaya).

Nuri Mahdi Arsyanti \& Sri Rahayu Tri Astuti. (2016). Analisis Pengaruh Kualitas Produk, Kualitas Layanan dan Keragaman Produk Terhadap Kepuasan Pelanggan Serta Dampaknya Terhadap Minat Beli Ulang (Studi Pada Toko Online Shopastelle, Semarang). Volume 5, Nomor 2, Issn (Online): 2337-3792.

Nyoman Wisniari Savitri. (2017). Pengaruh Celebrity Endorser Dan Iklan Melalui Media Televisi Terhadap Minat Beli Pada Tokopedia Di Denpasar. E-Jurnal Manajemen Unud, Vol. 6, No. 8, 2017: 42।4-423.

Penia Anggraeni \& Putu Nina Madiawati.(2016). Pengaruh Kepercayaan dan Kualitas Informasi Terhadap Keputusan Pembelian Secara Online Pada Situs www.Traveloka.com.eProceeding of Management:

Vol.3, No.2.

Philip Kotler \& Kevin Lane Keller.(2018). Manajemen Pemasaran. Jakarta. Penerbit Erlangga.

Rahmawati, (2018).“Pengaruh Harga dan Minat Beli terhadap Keputusan Pembelain Konsumen Shopee”.Jurnal Agora Vol. 5, No. I. 
Ratna Dwi Jayanti. (20I5). Pengaruh, Harga, Confidence, online Keputusan Pembelian online (Studi Kasus Pada Harapan Maulina Hijab Jombang ). Vol XNol.

Rosian Anwar \& Wijaya Adidarma."Pengaruh Kepercayaan Risiko Pada Minat Beli Belanja Online".

Sanny Hanjaya.(2016). Pengaruh Kualitas Produk, Pengetahuan Produk dan Keragaman Menu Terhadap Keputusan Pembelian Produk Capra Latte. Performa: Jurnal Manajemen dan Start-Up Bisnis Volume I, Nomor 2.

Selli Nisrina Faradila \& Dr. Harry Soesanto, MMR. (2016). Analisis Pengaruh Persepsi Kemudahan Penggunaan dan Persepsi Manfaat terhadap Minat Beli dengan Kepercayaan Sebagai Variabel Intervening (Studi pada Pengunjung Toko Online berrybenka.com di Kalangan Mahasiswa Universitas Diponegoro). Volume 5, Nomor 3 , ISSN (Online): 2337-3806.

Sudaryono. (2016). Manajemen Pemasaran: Teori \&Implementasi.Tangerang. Penerbit C.V Andi Offset.

Sugiyono.(2017). Metode Penelitian Bisnis.Bandung : CV Alfabeta.

Thamrin Abdullah, M.M., M.Pd. \& Francis Tantri, S.E., M.M. 2016. Manajemen Pemasaran. Jakarta. PT Rajagrafindo Persada.

Yunia Fitri Wahyuningtyas \& Dyah Ayu Widiastuti.(2015). Analisis Pengaruh Persepsi Risiko, Kemudahan dan Manfaat Terhadap Keputusan Pembelian Secara Online (Study Kasus Pada Konsumen Barang Fashion Di Facebook). Jurnal Kasian Bisnis Vol. 23, No.2. 